\title{
Joys and challenges of relationships in Scotland and New Zealand rural midwifery: a multicentre study.
}

CROWTHER, S., DEERY, R., DAELLENBACH, R., DAVIES, L., GILKISON, A., KENSINGTON, M., RANKIN, J. 


\title{
Joys and challenges of relationships in Scotland and New Zealand rural midwifery:
}

\section{a multicentre study}

\begin{abstract}
Background: Globally there are challenges meeting the recruitment and retention needs for rural midwifery. Rural practice is not usually recognised as important and feelings of marginalisation amongst this workforce are apparent. Relationships are interwoven throughout midwifery and are particularly evident in rural settings. However, how these relationships are developed and sustained in rural areas is unclear.
\end{abstract}

Aim: to study the significance of relationships in rural midwifery and provide insights to inform midwifery education.

Methods/design. Multi-centre study using online surveys and discussion groups across New Zealand and Scotland. Descriptive and template analysis were used to organise, examine and analyse the qualitative data.

Findings: Rural midwives highlighted how relationships with health organisations, each other and women and their families were both a joy and a challenge. Social capital was a principal theme. Subthemes were a) working relationships, b) respectful communication, c) partnerships, d) interface tensions, e) gift of time facilitates relationships.

Conclusions: To meet the challenges of rural practice the importance of relationship needs acknowledging. Relationships are created, built and sustained at a distance with others who have little appreciation of the rural context. Social capital for rural midwives is thus characterised by social trust, community solidarity, shared values and working together for mutual benefit. Rural communities generally exhibit high levels of social capital and this is key to sustainable rural midwifery practice. 
Implications. Midwives, educationalists and researchers need to address the skills required for building social capital in rural midwifery practice. These skills are important in midwifery pre- and postregistration curricula.

Key words: Rural, midwifery, relationships, social capital, sustainability, New Zealand, Scotland

\section{Statement of Significance:}

\begin{tabular}{|c|l|}
\hline $\begin{array}{c}\text { Problem } \\
\text { or Issue }\end{array}$ & There are continuing midwifery recruitment and retention concerns in rural regions. \\
\hline $\begin{array}{c}\text { What is } \\
\text { already } \\
\text { Known }\end{array}$ & $\begin{array}{l}\text { Relationships are at the heart of midwifery. Trusting relationships in rural midwifery } \\
\text { helps maternity services be safe and enjoyable }\end{array}$ \\
\hline $\begin{array}{c}\text { What this } \\
\text { paper } \\
\text { adds }\end{array}$ & $\begin{array}{l}\text { The significance of relationships for building and sustaining rural midwifery across two } \\
\text { enable sustainable rural midwifery. Midwives, educationalists and researchers need to } \\
\text { address the skills required for building social capital in rural midwifery practice. }\end{array}$ \\
\hline
\end{tabular}

\section{Introduction}

Globally, there is compelling evidence that recruitment and retention of skilled health care professionals remains a concern in middle to high income countries ${ }^{1}$ (e.g. in Canada ${ }^{2}$; Australia ${ }^{3}$; Scotland ${ }^{4}$; and New Zealand ${ }^{5}$ ).The remote and rural context poses unique challenges for midwifery practice and maternity services that warrant further exploration. The Royal College of Midwives (RCM) 2016 report on United Kingdom (UK) midwives 'Why midwives leave - Revisited' ${ }^{6}$, follows from a previous report done in 2002, continues to show that midwifery recruitment and retention. The 2016 report highlights a current short fall of 3500 midwives in the UK. This trend extends to the rural regions. The report highlights several concerns including staffing issues, bullying and ongoing disagreements between professional groups that continue to influence maternity services. In the 2016 World Health Organisation (WHO) global survey7, 'Midwives' voices, midwives' realities', 2500 midwives from 93 
countries reported professional and social economic barriers as influential to the delivery of safe, and effective maternity services. The survey highlighted concerns relating to dysfunctional relationships caused potentially by endemic staff shortages, overwork, power issues due to hierarchical institutional structures, inter-professional conflicts/dominance, gender inequalities, poor pay, lack of professional respect and paucity of professional development; some of which lead to reports of bullying in the survey. However, this may not apply to all regions globally. Kyle and Aileone's New Zealand report ${ }^{5}$ on rural staffing issues did not identify bullying and inter-professional disagreements being directly related to recruitment and retention. However, $X_{X X X X X X} s^{8,9}$ recent examination of rural maternity in New Zealand does suggest that there are communication tensions between professional groups which may be causing stress for some rural midwives again highlighting the significance of working relationships in rural practice.

This multi-centre study was undertaken to explore the practice realities of midwives working in remote and rural regions. Although there has been some focus on rural midwifery in terms of practice and policy much remains unknown about the reality of rural midwives' practice. This paper reports on some of the qualitative key findings from a mixed methods study undertaken across four sites: AUT University (Auckland, New Zealand), Ara Institute of Canterbury (Christchurch, New Zealand), the University of the West of Scotland and Robert Gordon University (Aberdeen, Scotland). The aim of the study is to contribute to knowledge that informs sustainable midwifery care provision for rural communities in both countries and provide insights into midwifery pre- and post-registration education curricula. This paper reports on one of the principal themes emerging from the qualitative data analysis - 'joys and challenges of relationships and social capital'. Future papers now in review will further explore the educational implications of this study. Using qualitative data from online discussion groups and responses to open questions in an online survey we explore this theme and its sub-themes in relation to what is already known and suggest implications arising from the study and recommendations for practice. 


\section{Literature review}

The complex issues surrounding rural maternity care have been examined in some depth, most commonly in the context of exploring the difficulties in recruiting and retaining qualified maternity care specialists in rural and remote settings $\mathrm{s}^{2,10}$. Among the challenges identified are the need to cover a small population over a large area ${ }^{11}$, issues around transfer times ${ }^{4,12,13}$ and the maintenance of skills 4,14-16. Nevertheless, while some issues associated with rural midwifery work have been identified, there remains a gap in fully understanding the overall experience of midwives working in rural settings or what sustains rural midwives, as well as a fuller picture of the issues they encounter.

One of the main issues identified by the literature was having to service a small population over a large geographical area ${ }^{17}$. The need to travel long distances takes a significant toll on midwives' time and influences the number of caseload numbers that can be taken on when compared to urban based practitioners ${ }^{18}$. This has financial implications where midwives are paid proportionately to the size of their caseload such as in the New Zealand system ${ }^{10}$. Working in relative isolation is not unusual given that General Practitioners (GPs), neonatal and obstetric services as well as secondary and tertiary facilities are located considerable distances away ${ }^{11}$. These long distances need to be accounted for when the need for transfers arise during pregnancy or childbirth ${ }^{4,12,14,19}$. This points to the professional and clinical need for optimal relationship based care to enhance positive collegiality locally and at distance $^{8}$. The need for workable pathways of communications is weaved throughout rural and remote midwifery, making relationships key to a sustainable service. Yet these relationships and lines of communication are often tested in ways that may not be encountered in urban centers ${ }^{8,20}$. The issue of a geographically dispersed client group and maternity services that are spread between rural and urban centers can be challenging.

Communication is therefore crucial for rural midwives and needs to be reflected in education and practice development. However, the need to engage in continuing professional education tends to be more difficult for those living in rural or remote areas. This is because the cost of travel to 
training/education courses, often held outside of the rural localities, added to which are the challenges of finding midwifery cover whilst out of the rural region when there are only a small group of practitioners covering a large area ${ }^{2,15,16,21}$. Organization of 'time away' requires rural midwives to have excellent networking and communication skills. Other educational issues relate to information access in regions where internet connections may be less developed, less stable and where libraries are not as well equipped ${ }^{16}$; this lack of connectivity can inhibit attempts to network and maintain relationships over distance. Rural midwives face many challenges due to their context. In another paper from the current study ${ }^{15}$, rural midwives demonstrated fortitude, resilience and resourcefulness when facing these unique contextual challenges.

What becomes evident in the literature is that relationships and communication in rural settings are crucial if rural midwifery services are to survive. There is an increasing body of literature about relationships based on trust in midwifery ${ }^{22}$ and where the positive potential of relationship based care can support women and contribute to better outcomes for women and their families (as well as midwives) ${ }^{23}$. Likewise, XXXXXXX and Smythe found open, trusting relationships and good interpersonal communication with colleagues and families facilitates safety in rural maternity ${ }^{8}$. For this trust and openness to flourish XXXXXXX and Smythe recommend that adequate, acceptable education and practice development options be made available in these regions that focus on building sustainable pathways of communications and relationships. How this will be best incorporated into educational midwifery pre- and post-registration programs remains unclear. The issues highlighted in the literature draw our attention to the uniqueness of rural midwifery and point to the significance of relationships.

\section{Participants, Ethics and Methods}

The study was undertaken in two stages. The first stage was an online survey using the application 'SurveyMonkey' and included 29 open and closed questions including Likert scales. After a broad list of questions was drawn up, the questionnaire was piloted with a small selection of rural midwives in New Zealand which enabled the questions to be refined and Likert scales to be developed. The second 
stage of the study, informed by the survey content, was online anonymised, asynchronous discussion groups that ran for 4 weeks in Scotland (one group) and New Zealand (two groups). This paper reports on themes revealed in the qualitative data through online discussion groups and the text data generated in the open questions in the survey.

\section{Context}

Context specificity and proportionality are crucial to appreciate the findings and conclusions of this study therefore the regional differences in both countries are highlighted. New Zealand and Scotland provide very useful contexts for comparison of rural midwifery practice because there are clear similarities regarding population, birth rate, geography, model of midwifery and midwifery education. In both countries, midwives take on the role of main professional for women with low risk pregnancies and provide community and hospital-based midwifery services to rural women. Further to this, recruitment and retention of rural midwives is a high concern in both countries which creates a problem for a sustainable maternity provision in rural areas ${ }^{4,5}$. Tables 1 and 2 summarises the contextual similarities and differences in midwifery care provision in the study sites.

(Position of table 1)

\section{Recruitment}

In Scotland, recruitment of participants was through midwifery leaders for each NHS Board who circulated the study details and survey link to all community midwives. Those midwives who worked in rural areas including those who worked in mixed rural/urban areas were invited via emails from their regional midwifery leads/managers to proceed with the online survey. The Scottish midwifery leads/managers were not aware of which midwives chose to participate as a link from the email linked directly to the online survey introductory page. New Zealand (NZ) midwives were recruited through the New Zealand College of Midwives (NZCOM) membership email list; the email likewise had a direct link to the online survey introductory page. NZ midwives were sent an invitation inviting those midwives currently, or who had in the past, worked with rural women. There were about 2500 
midwives on this general midwifery email list. There is no specific list for rural midwives in NZ. Table 2 shows the participants in each part of the study.

(Position of table 2)

\section{Ethics}

In Scotland, university ethical approval was obtained from XXX (XXXXXXXXXXX) and XXX (XXXXXXXX). Once secured, NHS Research and Development approval from each NHS Board was sought and granted to recruit staff for data collection. In New Zealand, ethical approval was granted through XXX (XXXXXXXX) Research Ethics Committee (XXXX) and then endorsed at XXX Human Research Ethics Committee. Information leaflets were sent out with initial invitation emails in both countries. Informed consent was then sought before data collection was started.

\section{Online survey}

In Scotland, an email was sent to all midwives deemed 'rural' by the midwifery managers in 13 of the 14 NHS Boards (one NHS Board declined to participate in the study). Midwives who responded were sent further information about the study. Those midwives who consented to participate in the study were sent individual log on details. Midwives who participated in the survey were given the opportunity to participate in the online discussion groups. The questions in the online survey were predominantly descriptive, for example, 'What is your main role as a rural midwife?' and questions pertaining to transfer arrangements and nature of any education/training preparation to take on the rural role. All midwives in both stages of the study were provided anonymity e.g. online pseudonyms were chosen by, or assigned, to the midwives. All NZ and Scottish midwives were requested to keep their personal identity and the identity of their workplace anonymous, so they could share their experiences safely and without breaching confidentiality and privacy. 


\section{Online discussion groups}

The closed, online, asynchronous groups were set up so that only those midwives who had given consent were formally admitted to the group. These discussions were asynchronous to ensure all midwives could contribute to discussions at times that suited them and enable researchers across twotime zones to follow discussions in both regions. The discussion group discussions were focused around five questions generated through the results of the survey (see table 4). An online environment presented a different opportunity for conducting focus groups with midwives. This was especially important given the international and remote and rural context of the study. Undertaking the discussion groups online was also less expensive than face to face discussion groups and they were less time consuming in terms of the midwives' time and travel. They also gave the research team greater access to a broad range of midwives. However, this was not the case once the study started. Whilst there was access to a broad range of midwives in Scotland there were only three midwives recruited to the online discussion groups in comparison to 12 midwives in New Zealand (Table 2). Two rounds of reminder emails were sent out to recruit more rural midwives onto the Scottish discussion forum without success.

(Position of table 4)

To adhere with ethical approval, maintaining anonymity was essential in light of the small numbers of midwives working within rural communities and personal demographic information obtained. Fear of recognition and censure has been shown to exist amongst rural midwives ${ }^{39}$, therefore care was taken not to identify participants and survey midwives were assigned numbers and forum discussion midwives pseudonyms.

(Position of table 2)

\section{Data analysis}

Textual (non-numerical) data were analysed using a qualitative descriptive approach informed by Braun \& Clarke $^{24}$ and the quantitative data was simple descriptive analysis (for participant's 
characteristics by country see Table 3). Qualitative data from the survey and online discussion groups were analysed using Kings' 'template analysis' ${ }^{25}$. Template analysis helped organise the findings as they emerged and provided a way of analysing data.

(Position of Tables 3)

The emergent template provided the initial descriptive themes for analysing the data from the online discussion groups. A coding template was then developed which summarised themes identified by the research team as significant in a data set and which were then organised in a meaningful way. Hierarchical coding was emphasised, using broad themes such as 'tensions between accountability and responsibility', encompassing successively narrower, more specific ones including 'changed relationships' and 'perceptions of risk'. The initial template was applied to the whole data set and modified. As analysis proceeded further emergent themes were identified. Themes were then compared, a process that increased the rigour of the study and encouraged a deeper analysis. Some of the codes were modified or discarded if they were not appropriate to the aims of the study. Throughout analysis the data were iteratively interrogated by the research team. The final themes were agreed by consensus amongst all researchers in all four centres via three face-to-face meetings and regular virtual meetings (see Table 5).

(Position for table 5)

\section{Findings}

\section{Characteristics of online survey participants}

Most of the midwives who responded to the survey worked as community midwives (Scotland) or as caseloading LMC midwives (New Zealand) with a small number employed in maternity facilities (see Table 3). All the midwives who identified their ethnicity in Scotland were either White Scottish, British or Irish. In New Zealand $13.1 \%$ of the midwives identified as Māori (the indigenous people of New Zealand) as compared to the national rate of $9.4 \%$ in the midwifery profession. The demographics of the rural midwives from New Zealand and Scotland were very similar in terms of age profiles and years 
in midwifery practice. In both cohorts, more than half of the midwives were aged 50 years or over and about a third in each group had more than 15 years of experience in rural midwifery practice. While this is indicative of the stability of the midwifery workforce, it also raises questions of its sustainability in terms of recruitment to replace midwives reaching retirement age. Assessing the degree of rurality by the time it takes for transfer from when the decision is made in the rural setting until arrival at the obstetric or neonatal facility, midwives in Scotland were working more remotely with almost $45 \%$ reporting transfer times in excess of 90 minutes compared to $26 \%$ in New Zealand.

Other questions that are relevant for the themes explored in this article include the reasons midwives noted for practising rurally and the relationship skills they considered to be important for rural midwifery practice. Midwives, particularly those from New Zealand, selected the response options of 'enjoying working with rural women' and 'wanting to ensure rural women could access midwifery services' as key motivations for them. Communication skills and collegial relationships with other midwives and health providers were rated as 'very important' on a Likert Scale by the majority of midwives in both countries. The principal theme 'Social Capital' and related sub-themes concerned with relationships are reported in this paper and illustrated in figure 1.

(Position of Figure 1: Principal theme, sub-themes and joys and challenges in rural midwifery)

\section{Working relationships}

Many midwives in the study, both on the online survey and discussion groups, cited relationships to be a source of joy but also brought challenges. Therefore, we asked more specifically about those relationships in the discussion groups. Subsequently a principal overarching theme identified was the significance of relationships and social capital. As Putnam ${ }^{26}$ has stated,

'... social capital refers to features of social organization such as networks, norms, and social trust that facilitate coordination and cooperation for mutual benefit'. (p.67)

Social capital thus became a useful theoretical framework to appreciate how these relationships functioned (or not) in rural maternity. The principal theme was therefore 'significance of social capital' 
and the sub-themes were a) working relationships; b) respectful communication; c) partnerships; d) gift of time facilitates relationships and e) interface tensions (figure 1).

Relationships with the organisation, each other and women and their families were both a joy and a challenge in a rural setting and were a common thread throughout the data. Some of these relationships were productive but some, especially those with colleagues in urban areas and the hospital, were more complex. Building strong collegial connections with other healthcare providers is viewed as vital by rural midwives in both countries. Midwives placed a high value on the relationships with the other midwives working in their area for sustaining their midwifery practice. A midwife from NZ noted her appreciation for:

Team work and understanding with my midwifery colleague. We have an understanding that we will come immediately when called without having to discuss, ask questions.

(Survey 8334, NZ)

A midwife from Scotland similarly commented:

We have a close-knit team that will always come if required and we trust each other. (Survey 1095, Scotland)

Good working relationships with local GPs, nurses, paramedics and other healthcare professionals provides opportunity for professional discussion, debriefing and sharing of resources. Midwives wrote about their embeddedness within their communities. One midwife lists the support services that she needs to be able to rely on:

Building workable relationships with other health providers is vital, including Pharmacist, local GPs, district nurses, ambulance staff, Well Child provider, Mental health, Breast feeding support, as well as building relationships with Police, local schools, Woman's groups for 
voluntary support networks, library. Even the local mechanic! If you need the car serviced....they have to understand the nature of "being on-call" 24/7 . (Survey 2836, NZ ).

This NZ midwife writes about how crucial relationships are when you are working alone:

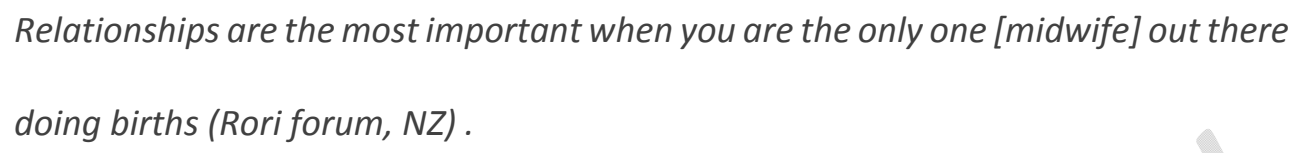

When asked what skill is important this Scottish midwife wrote about the importance of working relationships:

Very good, working knowledge of the area that I work in and good relationships with all local colleagues as well as the visiting Consultant Obstetricians. (Survey 9201, Scotland)

Developing and maintaining local knowledge and working relationships are crucial. Good working relationships come out of necessity and support rural midwives in providing care to women and their families. Midwives across both regions recognise that rural practice calls for a flexible approach and familiarity with referral processes, other professionals and colleagues that extend beyond midwifery practice. Sustaining these relationships calls for respectful communications.

\section{Respectful communication}

Respectful communication is understood as the cornerstone of best practice. This involves a way of communicating that demonstrates recognition and appreciation of each other's contribution to maternity care. However, this is not always the case and some midwives must work harder at times than other health professionals on building such relationships.

I always make a point of going into the local maternity unit when I am in town and asking how they are going. I don't ever get phone calls from them asking how I am! (Sarah forum, NZ) 
For several participants, the investment of time spent in cultivating collegiality has led to an increase in reciprocity. In rural settings midwives may find themselves sometimes having to work without a back-up of another midwife and be reliant on the goodwill and support of others in the locality through working partnerships.

\section{Partnerships}

Participants in New Zealand and Scotland reported job satisfaction when relationships with mothers, families and colleagues were fulfilling and reciprocal.

You know them, they know you. The ability to disseminate good practice, to be able to tailor to patient and family needs, and the demands of rural employment, farming/ fishing/partners away from home for work etc. To have access to the family. To know availability of informal support networks (Survey 5707, Scotland) I like knowing that the women have access to quality midwifery care in rural or even remote rural area's I am always felt like I a welcomed as an important part of the community. In rural area's it seems like everyone knows everyone, and you feel part of this close-knit community, seeing family's you have, or are, working with regularly in out of work situations. It seems like the more midwifery work you do the more family's you meet and become friends with! (Survey 3275, NZ)

This enjoyment was interconnected to the potential of providing midwifery continuity of carer in the rural setting:

I enjoy the smaller caseloads which often means "gold standard" midwifery care. I like being able to provide the whole range of care i.e. antenatal, intrapartum, and postnatal care. We get to know the women well as there is continuity of carer. (Survey 9202, Scotland) 
The power of relationships forged over time in rural regions shows itself in many ways. The words of the midwives in both countries suggest they felt valued and appreciated.

I feel more valued by women than I ever felt when working in a busy city hospital. Love working with women in rural areas. (Survey 2138, Scotland)

Rural families often seem to appreciate the midwifery partnership more than my town clients. They are often more respectful and realistic about logistics of midwifery being a valuable asset to the community. (Survey 6004, NZ)

As seen above when rural midwives are embedded into their communities and feel an integral part of that community there is job satisfaction and reciprocity. The quality of such relationships can bring joy to rural practice.

When midwife led care is facilitated, being able to support women and families in their home environment is very rewarding, and for me is the essence of why I became a midwife. (Survey 8276, Scotland)

The ability of rural midwives to get to know families and their local communities is rewarding. Being able to provide bespoke care that contributes to the health and wellbeing of that community inspires this Scottish midwife. Although this embeddedness into rural communities was experienced as a joy of rural practice it could also be a challenge.

You have the responsibility not for a shift or a ward but a community. I see young women who I delivered, I am introduced to people as the midwife that delivered you. I also quietly see the women who I supported when they miscarried or went through child protection cases. I am as linked to them as to the good outcomes. You carry a part of the community with you and there is no off switch. (Mary, forum Scotland) 
Although rural midwives were working for, and within a community, this meant that they were sometimes overly visible. Rural midwives in this study repeatedly described how they were often so integrated within their practice setting that they always carried the community with them. At times, this prohibited privacy or 'switch off' from their midwifery role.

\section{Gift of time facilitates relationships}

The data reveals a reward in rural practice born from the apparent gift of time which facilitates the flourishing of relationships in rural settings.

I like having the time to spend with women... I appreciate having travel time to consider my thoughts and feelings and to bring myself into a good space for whoever I am about to see (Survey 2865, NZ)

[l enjoy] developing relationship and trust with [women] \& their families...[being] able to spend good quality time with them throughout their pregnancies and postnatal period (Survey 0816, Scotland)

This gift of time afforded by working rurally enabled midwifery to be relationship based. Yet, the exact nature of how there is more time in rural practice for nurturing relationships is unclear. It is unclear if this relates to the midwife not being busy or rushed, although at times she can be very busy, or it is a consequence of the physical environment she traverses between practice encounters although covering geographical distance is very time consuming. Rural midwives might rationalise their time well and change their levels of commitment and involvement as rural and remote working dictate although midwives from Scotland in this study did not seem prepared to spend their off-duty time to assist with this research. From an environmental perspective, the physical space in and around rural midwifery practice might give the 'feeling' of spaciousness around time for relationships. Perhaps rural midwives working far from institutional demands become more deeply embedded in their rural community and are better at balancing work, family and community commitments making them 
strategic and selective with time. What is evident from the literature and this study is that there is something about the rural setting and mood of rural community living and working that means time can 'feel' and be prioritized differently. Time management in this study was shown to be challenging for rural midwives in both regions where vast distances needed to be traversed. This affected the amount of time invested in each episode of care thus potentially having a negative effect on building and sustaining relationships.

It can take half a day to attend one home postnatal visit' (Survey 7379, NZ)

Sometimes a postnatal visit can take up to 2.5 hours of travel alone

(Survey 2376, Scotland).

The gift of time and the challenges of distances appear to be in tension with each other on occasions and may undermine and facilitate relationships. Unfortunately, the discussion forum was unable to further tease out more depth of understanding about this phenomenon raising more questions about how the experience of time may be experienced differently in rural practice. Another potential tension in rural practice was at the interface with other local or urban colleagues.

\section{Interface tensions}

Tensions in practice, either between colleagues locally or with colleagues (medical and midwifery) who work in urban centres may emerge because of contextual misunderstanding. Working with other professional groups in rural communities is sometimes perceived as challenging by the participants in both countries. Midwife to midwife relationships can also be particularly challenging when professional partnerships are disconnected. One midwife comments:

There still can be individuals and/or some personalities that seem to be either defensive or critical of each other instead of working for the common service of providing a robust health/maternity service (Louisa, forum NZ) 
As one Scottish midwife stated such working relationships can lead to midwives working in isolation and thinking that the 'loneliness of single-handed practice along with a lack of shared best practice' can make rural midwifery unsustainable. Feeling lonely because of impaired collegial relationships locally can leave midwives feeling exposed and vulnerable with the potential for unsafe practice:

I'm left to manage situations alone that would have a whole team present in a bigger unit (Survey 1493, Scotland)

The interface with secondary and tertiary services is at times felt to be challenging. The participants in both countries refer to the lack of appreciation of rural practice on the part of their hospital based colleagues, who have easy access to obstetric and medical services. Similarities between the Scottish and New Zealand experience in relation to this interface tension were striking. One Scottish midwife outlined impoverished support as her main concerns:

Lack of support from colleagues in our Consultant Unit, the level of criticism of decision-making of the staff, the lack of manners when addressing midwives working in the rural setting, the lack of understanding of the challenges faced in the rural community setting (Survey 0712, Scotland).

Similarly, one of the NZ midwives describes how a lack of understanding and good communication exacerbates an already challenging situation:

Lack of understanding and communication from DHB [district health board] facility.

Often criticised by medical staff having dealt with very difficult situation with no support. Lack of understanding from medical staff of where we are situated rurally. (Survey 9254, NZ)

However, these adversarial encounters were countered with the recognition that caring communication can be established between the primary and secondary/tertiary sectors through cultivating good relationships with the team in the hospital. One of the NZ midwives praised the support received by the obstetric and urban midwifery support services: 
I maintain close professional relationships with Obstetrics and Gynaecology, Paediatricians, and staff at the local hospital which ensures smooth transfers. They are also a good source of advice and help (Sarah forum, NZ).

In Scotland decisions to transfer women to the mainland from island regions were often stressful and sometimes took several hours. For some rural midwives this stress is intensified by the paucity of opportunities to think through and discuss practice issues with colleagues in the same context, as one midwife states there is 'little local peer support to discuss cases' (Survey 8628, Scotland). The apparent supremacy of the hospital staff was evident in the way some of the rural midwives were treated when they arrived at the hospital. One Scottish midwife wrote about being treated with 'mild contempt' and then being 'sent on her way' without refreshments or the offer of a comfort break. Another midwife described being 'looked up and down with visible distaste' or even having overheard 'are you sure they are actual midwives?' Feeling unsupported and misunderstood was a recurring theme for Scottish rural midwives highlighting two different cultures with discordant beliefs and perspectives that did not enable communication and teamwork. This was not only a Scottish finding; this New Zealand midwife's narrative reflects similar challenges:

Several years ago I was asked to attend an APH, on arrival I had to tip toe through the blood it was everywhere, the woman was amazingly stable and baby still alive, but I insisted on a helicopter as the thought of a 4-5 hour ambu transfer with the potential for her to then prematurely labour was high. While we were waiting for the helicopter to arrive, the Reg called to blast me out for calling the helicopter and I quote "who gave you permission to order a helicopter, I'm going to have to explain this to my consultant". After staring at my phone for a minute I responded that the consultant should speak to me as I'm the prime health professional on the ground making the assessment and only I am in a position to decide on the mode of transport. He cut me off! (Alice forum, NZ) 
This tension between rural and urban services was highlighted when disruption and disconnection to the relationship with women occurred; especially during transfers when Scottish midwives were expected to leave women once transferred to urban hospital carers.

Unfortunately, we are expected to leave the patient almost immediately as we are required to return home with the ambulance. They cannot wait for us and although could have a quick break, are expected to get back to their own area asap. That is unless there is an emergency call nearby and we are sent to attend that, which has been interesting on occasion. It would be lovely to stay with the woman both for midwife but also for patient, as you see them in tears sometimes as we hand over and leave pretty quickly. Even without returning with the ambulance, we have to return to the remainder of our own caseload. (Sheelagh forum, Scotland)

These interface tensions can also surface locally. Another area of challenge for rural midwives was maintaining relationships with agencies such as the police and social workers, whilst equally preserving the relationship with the woman and ensuring client confidentiality. There is a growing need in policy and public health agendas for maternity to work in more and more integrative ways with social services and related community agencies. This need to work in cross boundary collaborative ways is essential in rural regions and this requires excellent communication pathways and optimal collegial relationships. However, there can be tensions when social issues are encountered which can create barriers to open, trusting relationships creating further conflict in an already complex situation. These tensions were highlighted in a New Zealand discussion group around the metaphor of being "In $a$ sandwich as a midwife" (Rori forum, NZ) or as Sheeren (forum, NZ) states, "I have felt at times like a "sandwich filling" when there is child protection agency involvement"

The potential for conflict of interest is real when everyone knows everyone in a small rural community. For example, one midwife shared how the police questioned her about drug trafficking in a home where she was visiting a woman in her care. The midwife stated that she had a duty of care to the 
woman which involves the issue of confidentiality, but she also considered that her relationship with the local police is important in the long term. Shereen (forum, NZ) further explains how she normally provides a family with options in these delicate situations:

\section{... [I give the] option of informing [the agency] as early as possible with a view to preventing any institutional panic reaction as baby's arrival approaches and to institute supportive measures. (Shereen forum, NZ)}

The expectation that rural midwives can contend with every eventuality with the limited resources to hand is unrealistic. In the words of one of the midwives in Scotland 'cases just turn up' suggesting that unpredictability contributes to the potential for creating tension around who is responsible and accountable.

The development and maintenance of professional skills are both challenging and in need of careful consideration. In this study, the notion of 'expertise' and the uniquely skilled qualities of rural midwives, of which building and maintaining a network of professional relationships both within a rural setting and with others far away, is often not held in high esteem when compared to colleagues in urban centres. However, what is evident in this study is that the skill of open, trusting collegial relationships with other midwives, agencies and services locally and at distance is a skill that ensures a sense of community solidarity and shared purpose that lies at the heart of sustainable, safe, rural practice.

\section{Discussion}

This paper has highlighted the significance of relationships in rural midwifery practice across two countries - Scotland and New Zealand. Although both regions have different maternity infrastructures, midwives in both countries highlight the importance of relationship. Whilst relationship is at the heart of all rural and urban midwifery settings there are some differences worth examining more closely in the rural context. 
This study draws attention to cultural and communication differences and an occasional lack of mutual understanding amongst maternity care providers. Urban reality is that midwives and other health professionals are trained to work in teams and to work shift patterns which is different to the realities of remote and rural working practice. Not only do rural midwives build awareness of relationships in the community's diversity they also have to maintain integrative and mutually supportive relationships with many health professionals. Congruent with the findings of this study, XXXXXXX and Smythe ${ }^{8}$ highlighted the importance of open, trusting relationships in rural regions to ensure safety for women and babies. However, across both countries midwives suggest that social connections are not always trusting, respectful, honest and competent between midwives and other health professionals.

Deery and Fisher ${ }^{27}$ contend that relationships in midwifery have at times been overshadowed by social and economic determinants, for example, the continual emphasis on quantifiable targets, efficiency savings and centralising maternity provision. This is concerning given that midwives in this study reveal how relationships in rural practice need to be given significance and be nurtured for a sense of community solidarity and social trust to develop. Social trust is a fundamental constituent of social capital, and in this context, is concerned with how midwives can trust and rely on those they work with. Social trust thus builds a sense of social integration with others they work with to promote co-operative ways of working together towards a common goal based on shared values, collective activities, and feeling of social bonding and kinship with members of the community. Although this would be true for midwives in urban practice too it is evident that this has more significance when practicing in geographical isolation. This study highlights how rural midwives need to have trust in the reliability and integrity of colleagues (near and far) for a sense of community and collective solidarity to grow which helps safeguard enjoyable and safe rural practice. They need to feel part of a congenial supportive community of practice even when practising alone.

The notion of embeddedness with a community, the physical and emotional interconnectedness within community, previously shown in Patterson's work ${ }^{45}$ resonates with the findings of this study. However, some midwives find this embeddedness challenging at times and this has been reflected in 
other studies ${ }^{9,45}$. For some rural midwives this embeddedness is experienced as a daily high level of personal and professional exposure in their communities limiting the amount of anonymity they can maintain within the community. This can mean that the midwife does not get much respite from her professional role.

Embeddedness highlights how relationships and 'knowing each other' over time and 'caring' for the community' as a member of that rural community are at the heart of rural practice. Adler and Proctor ${ }^{28}$ suggest, "We are likely to develop relationships with people we interact with frequently. In many cases, proximity leads to liking." (254). However, this 'liking' cannot be guaranteed. Adler and Proctor's thesis is that those who are in proximity to our everyday lives are often more similar in their outlook and appreciate many of the social and economic concerns of the community and share similar values. They also suggest that this physical proximity is often more powerful than any virtual proximity afforded by modern technology (e.g. social media, VC, mobile phones). This has implications for the rural midwife who often relies on technology in practice to communicate.

Yet relationships may not always be easy to maintain in small rural communities. For example, when the professional accountability of the rural midwife is not consistent with a person(s) in that community; such as in a family violence and child protection situation. This situation has been referred to as professional dissonance where conflicting values and beliefs interfere with relationship based care $^{29}$. Maintaining open pathways of communication in such circumstances can be challenging in small rural communities where anonymity is difficult. The potential for conflicting expectations in regions where choice may be limited (e.g. care provider, choice of colleagues, skill mix and place of birth) may influence the development of competent relationships and how they are established and maintained. Negotiating multiple relationships between diverse maternity care settings whilst maintaining personal and professional boundaries is peculiar to a rural setting due to geographic location. For example, the rural midwife may be the only local professional negotiating a challenging practice situation in which she must act as the middle person between different contexts and with colleagues she has never met, as one midwife said she can feel, 'like a sandwich filling'. 
Unsurprisingly, positive and meaningful working relationships can impact on the well-being of a whole family that a midwife is caring for, and positively or negatively affect health outcomes and psychological safety ${ }^{30-32}$. This impact has also been shown to be mirrored in the rural midwife's own family ${ }^{10}$, a phenomenon requiring further investigation. Relationships hold rural practice together, and these relational encounters may manifest in simple ways, e.g. when a midwife is tired and needs to sleep and a colleague or family member makes a cup of tea the midwife will feel cared for and appreciated. Midwives have been found to feel less stressed the more control they have over their working conditions and when they work in supportive and collegial workplaces ${ }^{8,33,34}$.

Continuity of midwifery care in rural areas is not new and is central to many rural midwives where a few midwives (or possibly one) work with a small community over time sharing and learning about the community's cultural and social values. A key factor in providing midwifery continuity of care(r) is developing meaningful relationships with women and families, often established over months and/or years, ${ }^{35,36}$ these relationships have been shown to improve health outcomes for mothers and infants 34,35. Unsurprisingly continuity of carer midwifery models across settings have repeatedly demonstrated enhanced reciprocal relationships $9,37,38,41,42$. Continuity of carer lies at the heart of New Zealand midwifery across all regions and has been shown to build a sense of belonging and connectedness for New Zealand rural midwives ${ }^{8,39}$. This unique experience of NZ rural midwives has been identified previously and linked to how rural midwives develop a strong connection with their local community ${ }^{40}$ so it was not a surprise to see this highlighted again in this study. However, the Scottish midwives in this current study also describe how relational continuity provides joy to their rural practice and connection to the community in which they work; despite a very different maternity infrastructure.

Participants in this study worked in ways that prioritise these relationships which appeared to improve their sense of autonomy, accountability, responsibility and trust; experiences mirrored in other studies. Patterson ${ }^{45}$ found that New Zealand midwives felt connected and responsible for the wellbeing of the women in their region and described this as both a privilege and a great responsibility. 
The level of autonomy and responsibility about the safety of their clients is something participants felt is not fully appreciated by other medical professionals or their urban counterpart; a finding highlighted in previous studies ${ }^{4,40}$. Accountability has also been identified previously as increasing performance pressure in the face of potential for negative pregnancy outcomes, which in a small community where there is increased visibility, can come at a high personal cost ${ }^{4,34}$.

Midwives in this study have demonstrated the expert skill of bridging relationships and creating open trusting communications alongside unique contextual challenges which they encounter in everyday practice ${ }^{15}$. Both evidence and health policy support the value of relational models of care yet bringing these into practice in all regions in an equitable and sustainable way is the ongoing challenge.

Rural communities and maternity care are dependent on a myriad of other services and agencies that are often remote. Healthy relationships, whether professional or personal, need to be open to solutions based on shared values which facilitate better opportunities for working together for mutual benefit. The findings in this study highlight the characteristics of social trust, community solidarity, shared values and working together for mutual benefit; all of which constitute social capital. Social capital therefore lies at the heart of sustainable safe rural midwifery.

\section{Implications for practice}

There are lessons to be learned by the midwifery systems in New Zealand and Scotland. Acknowledgement by senior leaders/managers and policy makers that relationships and the time invested in these relationships is important for all midwives and is a particularly vital for rural midwives. Models of midwifery care based on relational continuity need to be developed in each region. For rural midwifery services to survive there is a need for pre-and post-registration education for rural midwifery to focus on the importance of fostering relationships with women, families, the community, and other health professionals. Functional relationships are fundamental to rural midwifery practice in terms of sustainability for the midwife, and for ensuring good inter-professional working relationships as this is pivotal to the provision of safe rural maternity care. These educational 
activities need to be extended to urban based practitioners also to help overcome many of the misunderstandings between these different contexts. Provision of resources that facilitate the development of these skills (e.g. educational, inter-professional connectivity, invitation to relevant fora as well as time and financial support to engage with these opportunities without disadvantaging rural midwives) is essential.

\section{Strengths and limitations}

In terms of data collection, the online asynchronous discussion groups provided a safe environment for the midwives to share their experiences of rural midwifery. However, a limitation is that only three midwives in Scotland contributed to the focus groups, despite all but one of the 14 NHS Boards agreeing to participate. This limited sample in Scotland prevented true comparison with designated rural midwives in NZ. It could be argued that Scottish midwives' reluctance to engage in work (in this case, the discussion groups) outside of their work hours potentially influenced the recruitment of Scottish midwives and was subsequently problematic. Data from New Zealand midwives suggest that their midwifery system facilitates better connections and responsibility for the well-being of the women and they described this as both a privilege and a great responsibility. The data suggest that time was less of an issue in NZ and there was less imperative for work time to have demonstrable outcomes being privileged over social solidarity. This clearly illustrates that any maternity service infrastructure needs to be in harmony and nurture the relational care models of midwifery care for a midwifery workforce to be sustainable; this is no less important for midwives working with rural communities. Also, health and social care contexts, nationally and internationally, where organisational and hierarchical forms of managerialism exist (e.g. in the NHS in the UK) may be detrimental to enhancing social capital, ${ }^{33}$ lessoning social trust and collective solidarity.

\section{Further research}

An in-depth examination of rural midwifery using the sociological theoretical framework of social capital would afford further insights. For example, although prioritising time for relationships is an 
interesting finding in this study it is tentative and merits further exploration. How these findings could be translated into educational programs is necessary. What are the optimal educational and practice development resources required for building and nurturing professional relationships in rural midwifery practice? To answer this further work is needed to identify and describe what specific skills are required for building social capital in different contexts. This work would then be beneficial to future educational approaches that support sustainability of rural midwifery services. Further research is also needed to explore different ways of engaging Scottish midwives in research. Secondary data analysis is planned with this question in mind.

\section{Conclusion}

This paper has foregrounded the joys and challenges of relationships in two different rural midwifery settings; Scotland and New Zealand. Many of the relationships are with people in the same rural community and enjoy frequent proximity. Midwife-woman relationships in rural settings are often nurtured over time through midwifery continuity of carer. Many other professional relationships are created, built and sustained at a distance, often with others who have little or no appreciation of the rural context. At times relationships with other members of the maternity team are not easy yet rural midwives have no choice but to nurture collegial working relationships even when there is discord. Their rural practice requires good communication networks with many people near and far and skill in building social capital. Rural communities generally exhibit high levels of social capital and this is key to safe and enjoyable rural midwifery practice. Social capital for rural midwives is characterised by social trust community solidarity, shared values and working together for mutual benefit. It is therefore important that educational, practice and personal development incorporates the skill of building and sustaining social capital as part of the tool kit of rural midwifery practice. This will contribute to a sustainable rural midwifery service, benefitting women, their families and the midwives who work in partnership with them. 


\section{Acknowledgements}

There was no funding provided for this study. The research team are grateful for the generosity of all midwife participants across New Zealand and Scotland who volunteered to participate and make this study possible.

\section{REFERENCES}

1. Lehmann U, Dieleman M, Martineau.T. Staffing remote rural areas in middle- and low-income countries: a literature review of attraction and retention. BMC Health Serv Res 2008; 8(19).

2. Kornelsen J. Rural midwifery: Overcoming barriers to practice. Canadian Journal of Midwifery Research and Practice 2009; 8: 6-11.

3. Fisher K, Fraser J. Rural health career pathways: Research themes in recruitment and retention. Australian Health Review 2010; (34): 292-96.

4. Tucker J, Kiger A, Hundley V, et al. Sustainable maternity services in remote and rural Scotland? A qualitative survey of staff viewson required skills, competencies and training. Quality and Safety in Health Care 2005; 14: 34-40.

5. Kyle M, Aileone L. Mapping the rural midwifery workforce in New Zealand. In: Zealand HWN, editor.; 2013.

6. Royal College of Midwives. Why midwives leave - Revisited. In: RCM, editor. London; 2016.

7. World Health Organisation. Midwives' voices, midwives' realities. Geneva: WHO; 2016.

8. Crowther S, Smythe L. Open, trusting relationships underpin safety in rural maternity a hermeneutic phenomenology study. BMC Pregnancy and Childbirth 2016; 16(370).

9. Crowther S. All is not as it first may seem: Experiences of matenity in rural and remote rural regions in New Zealand from the perspectives of families and health care providers. Auckland, NZ: AUT University, 2015.

10. Crowther S. Providing rural and remote rural midwifery care: an 'expensive hobby'. Midirs Midwifery Digest 2017; 27(1): 128. 
11. Adair A, Coster H, Adair V. Review of International and New Zealand Literature Relating to Rural Models of Care, Workforce Requirements and Opportunities for the Use of New Technologies: Commissioned by The New Zealand Institute of Rural Health, 2012.

12. Munro S, Kornelsen J, Grzybowski S. Models of maternity care in rural environments: Barriers and attributes of interprofessional collaboration with midwives. Midwifery 2013; 29(6): 646-52.

13. Kornelsen J, Grzybowski S. Is local maternity care an optional service in rural communities? JOGC 2005; 24

14. Cheyne H, Dalgleish L, Tucker J, et al. Risk assessment and decision making about in-labour transfer from rural maternity care: a social judgment and signal detection analysis. BMC Medical Informatics and Decision Making 2012; 12(1): 122.

15. XXXXX et al 2018 xxxxxxxxxxxxxx (by current authors)

16. Ireland J, Bryers $\mathrm{H}$, van Teijlingen $\mathrm{E}$, et al. Competencies and skills for remote and rural maternity care: a review of the literature. Journal of Advanced Nursing 2007; 58(2): 105-15.

17. National Health Committee. Rural Health: Challenges of Distance, Opportunities for Innovation. Wellington: NZ: National Health Committee, 2010.

18. Redshaw M, Hamilton K, Rowe R, Jomeen J, Newburn M. Maternity care in rural areas: Key issues. Perspective - NCT's journal on preparing parents for birth and early parenthood 2012; June: 126.

19. Patterson J, Skinner J, Foureur M. Midwives decision making about transfers for 'slow' labour in rural New Zealand. Midwifery 2015; 31(6): 606-12.

20. Harris FM, van Teijlingen E, Hundley V, et al. The buck stops here: Midwives and maternity care in rural Scotland. Midwifery 2011; 27(3): 301-7.

21. Crowther S. Providing rural and remote rural midwifery care: an 'expensive hobby'. New Zealand College of Midwives Journal 2016; (52): 26-34.

22. Kirkham M. The Midwife-Mother Relationship. London: Palgrave Macmillan Limited; 2010.

23. Lewis $M$, Jones A, Hunter B. Women's experience of trust within the midwife-mother relationship. International Journal of Childbirth 2017; 7(1): 40-52.

24. Braun V, Clarke V. Using thematic analysis in psychology. Qualitative research in psychology 2006; 13(2): 77-101. 
25. King N. Doing template analysis. Qualitative organizational research: Core methods and current challenges 2012; (426): 77-101.

26. Putnam RD. Bowling alone. The collapse and revival of American community. New York: Simon and Schuster; 2000.

27. Deery R, Fisher P. Professionalism and person-centredness: developing a practice based approach to leadership within NHS maternity services in the UK. Health Sociology Review 2016.

28. Adler R, Proctor R. Communication and relational dynamics. In: Adler R, Proctor R, eds. In Looking out looking in. 14 ed. Boston, MA: Wadsworth: Cengage Learning.; 2014: 248-75.

29. Deery R, Hunter B. Emotion Work and Relationships in Midwifery. In: Kirkham M, ed. The Midwife-Mother Relationship. 2 ed; 2010: 37-54.

30. Hunter B, Deery R, editors. Emotions in midwifery and reproduction. NY: Palgrave Macmillan; 2009.

31. Walsh D. Improving Maternity Services: Small Is Beautiful - Lessons from a Birth Centre: Radcliffe Publishing; 2006.

32. Renfrew M, Homer C, Downe S, et al. Midwifery series: Executive summary: The Lancet; June 2014.

33. Deery R, Fisher P. Professionalism and person-centredness: developing a practice based approach to leadership within NHS maternity services in the UK. Health Sociology Review 2016.

34. Crowther S, Smythe E, Spence D. Unsettling moods in rural midwifery. Women and Birth 2017; In Press(0): 0.

35. Homer CS, Leap N, Edwards N, Sandall J. Midwifery continuity of carer in an area of high socioeconomic disadvantage in London: A retrospective analysis of Albany Midwifery Practice outcomes using routine data (1997-2009). Midwifery 2017; 48: 1-10.

36. McAra-Couper J, Gilkison A, Crowther S, Hunter M, Hotchin C, Gunn J. Partnership and reciprocity with women sustain lead maternity carer midwives in practice. New Zealand College of Midwives Journal 2014; (49): 27-31.

37. McCourt C, Stevens T. Relationship and reciprocity in caseload midwifery. In: Hunter B, Deery R, eds. Emotions in midwifery and reproduction. NY: Palgrave Macmillan; 2009: 17-25.

38. Lewis M, Jones A, Hunter B. Women's Experience of Trust Within the Midwife - Mother Relationship. International Journal of Childbirth 2017; 7(1): 40-52. 
39. Patterson J. Off the Beaten Track: a Postmodern Feminist Analysis of Rural Midwifery and Rural Media Health Discourses. Wellington, New Zealand: Victoria; 2002.

40. Patterson J. Rural midwifery and the sense of difference. New Zealand College of Midwives Journal 2007; (37): 15-8. 
Figure 1: Principle theme, sub-themes and joys and challenges in rural midwifery

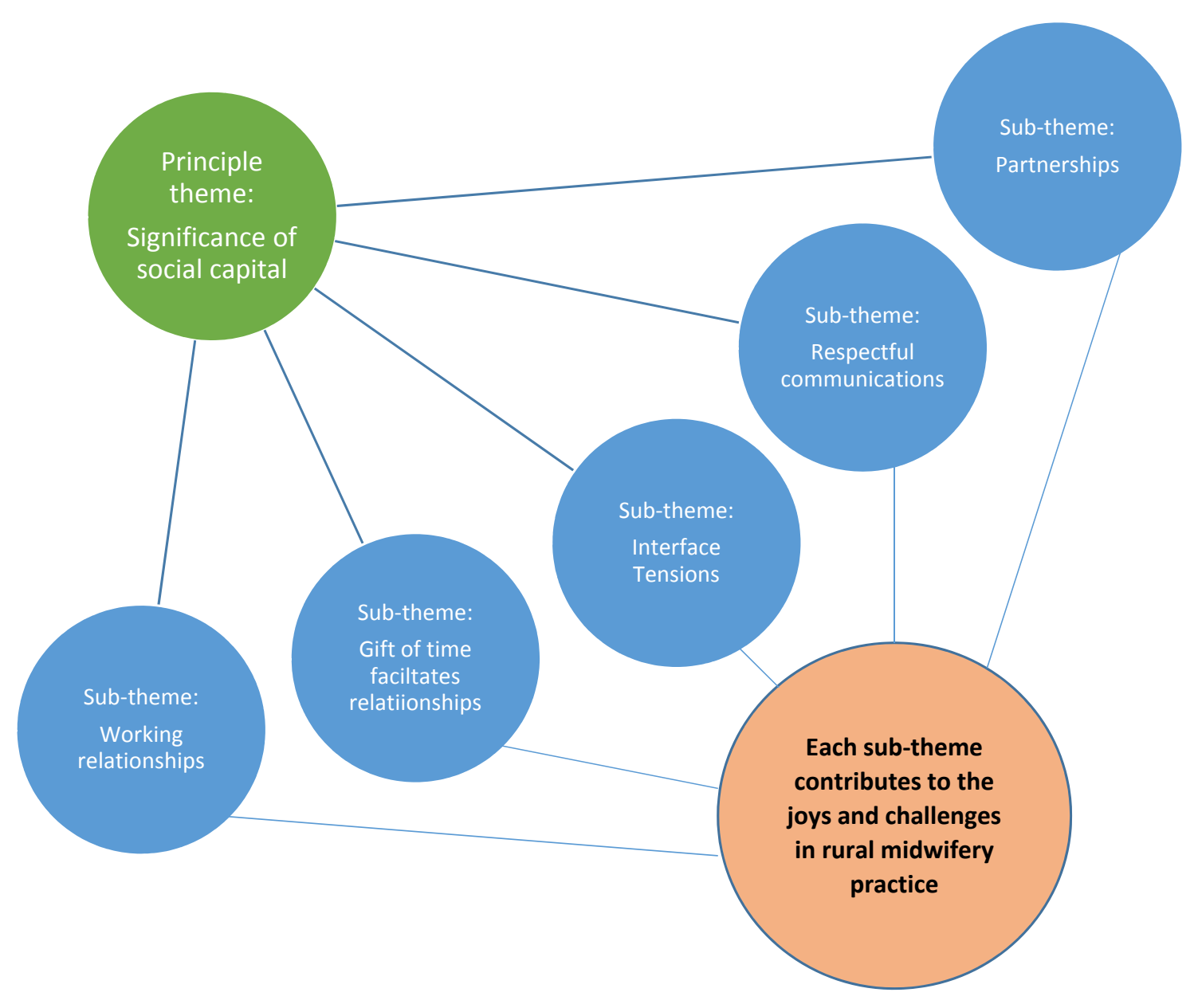


Table 1. Similarities between New Zealand (NZ) and Scotland

\begin{tabular}{|c|c|}
\hline Population & 4.693 million (NZ) and 5.295 million (Scotland) \\
\hline $\begin{array}{l}\text { Birthrate } \\
\text { (live births) }\end{array}$ & $\begin{array}{l}\text { New Zealand 62,000 live births/year (on average) } \\
\text { Scotland } 55100 \text { live births/year (on average) }\end{array}$ \\
\hline Terrains & Rugged landscape, with similar terrains in South Island and Scotland \\
\hline $\begin{array}{l}\text { Registering } \\
\text { body }\end{array}$ & Midwifery Council of NZ, Nursing and Midwifery Council (UK) \\
\hline $\begin{array}{l}\text { Professional } \\
\text { body }\end{array}$ & $\begin{array}{l}\text { New Zealand: New Zealand College of Midwives } \\
\text { Scotland: Royal College of Midwives (UK wide) }\end{array}$ \\
\hline $\begin{array}{l}\text { Maternity } \\
\text { care model }\end{array}$ & $\begin{array}{l}\text { Midwife-led and women-centred care models are promoted. Midwives } \\
\text { are identified as lead carer and accountable for providing low risk } \\
\text { uncomplicated maternity care } \\
\text { (i.e. Lead Maternity Carer (LMC) in NZ and Named Midwife in Scotland) }\end{array}$ \\
\hline $\begin{array}{l}\text { Midwifery } \\
\text { education: }\end{array}$ & $\begin{array}{l}\text { Midwifery education provides both pre-registration and post-registration } \\
\text { Education (at undergraduate and postgraduate levels). } \\
\text { Education involves rural/provincial sites for placement of student midwives } \\
\text { in their own community }\end{array}$ \\
\hline $\begin{array}{l}\text { Current } \\
\text { issues }\end{array}$ & $\begin{array}{l}\text { Recruitment and retention of midwives to work in rural areas is a common } \\
\text { problem with the ongoing issue in providing sustainable maternity services. }\end{array}$ \\
\hline
\end{tabular}

Table 2. Participant numbers in each stage of the study

\begin{tabular}{|l|l|l|}
\hline Stage of study & Scotland & New Zealand \\
\hline Online survey & 77 & 145 \\
\hline Online discussion groups & 3 (1 group) & 12 (2 groups) \\
\hline
\end{tabular}


Table 3: Participants' Characteristics by Country

\begin{tabular}{|c|c|c|c|}
\hline Characteristics & $\begin{array}{c}\text { New Zealand } \\
\mathrm{n}(\%) \\
\end{array}$ & $\begin{array}{c}\text { Scotland } \\
\mathrm{n}(\%)\end{array}$ & $\begin{array}{l}p \text { value }\left(X^{2}\right) \\
<0.05\end{array}$ \\
\hline $\begin{array}{l}\text { Rural midwifery work type }(\mathrm{n}=\text { number } \\
\text { responding)* }\end{array}$ & 144 & 77 & \\
\hline $\begin{array}{l}\text { Case loading self-employed or employed } \\
\text { (LMC) }\end{array}$ & $108(75 \%)$ & & \\
\hline Core midwife & $18(12.5 \%)$ & & \\
\hline Core midwife and case loading & $5(3.5 \%)$ & & \\
\hline Rural locum midwife (Case loading or core) & $12(8.3 \%)$ & & \\
\hline Midwifery educator & $1(0.7 \%)$ & & \\
\hline Community midwife incl. labour and birth & & $51(66 \%)$ & \\
\hline Community midwife mainly ante/postnatal & & $26(34 \%)$ & \\
\hline Ethnicity (n) NZ & 122 & 65 & \\
\hline New Zealand Maori & $16(13.1 \%)$ & & \\
\hline New Zealand European & $86(70.5 \%)$ & & \\
\hline Other European & $34(27.9 \%)$ & & \\
\hline Other & $7(5.7 \%)$ & & \\
\hline White Scottish & & $50(76.9 \%)$ & \\
\hline White Other British & & $14(21.5 \%)$ & \\
\hline White Irish & & $1(1.5 \%)$ & \\
\hline Age $(n)$ & 120 & 65 & NS** \\
\hline$<30$ & $6(5 \%)$ & $3(4.6 \%)$ & \\
\hline $30-49$ & $50(41.7 \%)$ & $26(43 \%)$ & \\
\hline$\geq 50$ & $64(53.3 \%)$ & $34(52.4 \%)$ & \\
\hline Mean year of registration & 1997 & 1995 & NS \\
\hline Years in rural midwifery practice $(\mathrm{n})$ & 120 & 65 & NS \\
\hline$\leq 5$ years & $39(32.5 \%)$ & $14(21.5 \%)$ & \\
\hline $6-10$ years & $23(19.2 \%)$ & $14(21.5 \%)$ & \\
\hline $11-15$ years & $20(16.7 \%)$ & $14(21.5 \%)$ & \\
\hline$>15$ years & $38(31.7 \%)$ & $23(35.4 \%)$ & \\
\hline $\begin{array}{l}\text { Transfer time from decision to arrival in } \\
\text { obstetric/ neonatal facility ( } \mathrm{n} \text { ) }\end{array}$ & 138 & 67 & $<0.05$ \\
\hline$\leq 60$ minutes & $62(44.9 \%)$ & $25(37.3 \%)$ & \\
\hline $61-90$ minutes & $40(29 \%)$ & $12(17.9 \%)$ & \\
\hline$>90$ minutes & $36(26.1 \%)$ & $30(44.8 \%)$ & \\
\hline Reasons for rural midwifery $(\mathrm{n})$ & 145 & 77 & \\
\hline Live rurally & $104(71.7 \%)$ & $43(55.8 \%)$ & 0.025 \\
\hline Enjoy working with rural women & $91(62.8 \%)$ & $30(39 \%)$ & 0.001 \\
\hline To ensure access to midwifery care & $92(63.4 \%)$ & $29(37.7 \%)$ & $<0.001$ \\
\hline Enjoy rural lifestyle & $74(51 \%)$ & $35(45.5 \%)$ & NS \\
\hline Grew up in a rural area & $40(27.5 \%)$ & $21(27.3 \%)$ & NS \\
\hline Connection to this rural community & $56(38.6 \%)$ & $28(36.4 \%)$ & NS \\
\hline Required interpersonal skills (n) & 125 & 67 & \\
\hline Communication skills (very important) & $115(92 \%)$ & $62(92.5 \%)$ & NS \\
\hline $\begin{array}{l}\text { Collegial relationships with other midwives } \\
\text { (very important) }\end{array}$ & $113(90.4 \%)$ & $58(86.6 \%)$ & NS \\
\hline $\begin{array}{l}\text { Collegial relationships with GPs and health } \\
\text { providers (very important) }\end{array}$ & $76(60.8 \%)$ & $48(71.6 \%)$ & NS \\
\hline
\end{tabular}


TABLE 4: FIVE QUESTIONS POSED TO PARTCIPANTS IN DISCUSSION GROUPS BASED ON SURVEY RESULTS

- Can you describe the shape (e.g. demographics, geography and economics) of the rural community that you work?

- Respondents in the survey talked about the importance of relationships with other health professionals, community groups, Police and/or Child/Social services. What are some of your experiences?

- Many respondents in the online survey outlined the challenge of the rural/urban interface. Can you please tell us about some of your experiences?

- What specific skills stand out as being essential to rural midwifery practice? What is the point of difference to an urban midwife?

- How were you prepared in your pre-registration education and post-registration education to cope with situations you face working rurally? 
Table 5: Results of template analysis

\begin{tabular}{|c|c|c|}
\hline $\begin{array}{l}\text { Over all } \\
\text { themes }\end{array}$ & Principle themes & Sub themes \\
\hline \multirow[t]{2}{*}{$\begin{array}{l}\text { Joys and } \\
\text { challenges }\end{array}$} & Social capital & $\begin{array}{l}\text { - Working relationships } \\
\text { - } \text { Respectful communication } \\
\text { - Partnerships } \\
\text { - Gift of time facilitates relationships } \\
\text { - Interface tensions }\end{array}$ \\
\hline & Practice realities & $\begin{array}{l}\text { - Autonomy of rural midwifery } \\
\text { - Appreciation of rural women and the community } \\
\text { - Beauty and a personal connection to the countryside/ } \\
\text { land } \\
\text { - Impact of travel distances, topography and } \\
\text { connectivity } \\
\text { - Commitment to equity for rural women }\end{array}$ \\
\hline \multirow[t]{2}{*}{$\begin{array}{l}\text { Courage and } \\
\text { fortitude }\end{array}$} & Unique skill set & 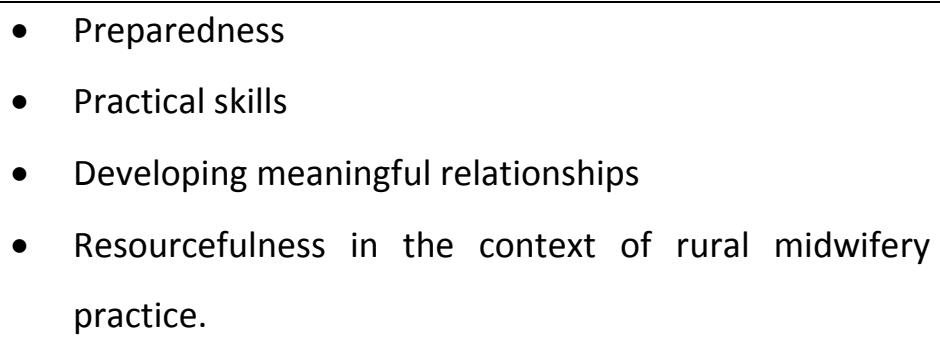 \\
\hline & Safeguarding & $\begin{array}{l}\text { - } \quad \text { Sustaining self } \\
\text { - Safeguarding women and families }\end{array}$ \\
\hline \multirow[t]{2}{*}{$\begin{array}{l}\text { Future } \\
\text { proofing rural } \\
\text { practice }\end{array}$} & $\begin{array}{l}\text { Preparation for } \\
\text { rural practice }\end{array}$ & $\begin{array}{l}\text { - } \quad \text { Confidence in normal physiological birth } \\
\text { - } \quad \text { Prepared, anticipate and respond } \\
\text { - } \quad \text { Rural specific education } \\
\text { - } \quad \text { Learning from stories from rural midwives } \\
\text { - } \quad \text { Rural placement alongside a midwife }\end{array}$ \\
\hline & $\begin{array}{l}\text { Living the } \\
\text { experience and } \\
\text { seeing the reality }\end{array}$ & $\begin{array}{l}\text { - } \text { Relative isolation } \\
\text { - } \quad \text { The enormity of the responsibility } \\
\text { - } \quad \text { Rural women are different } \\
\text { - } \quad \text { Being adaptable and making do }\end{array}$ \\
\hline
\end{tabular}

